\title{
From an Academician's Preschool Diary: Emergent Curriculum and Its Practices in a Qualified Example of Laboratory Preschool
}

\author{
Özge Metin Aslan ${ }^{1, *}$ \\ ${ }^{1}$ Faculty of Education, Alanya Alaaddin Keykubat University, Alanya-Antalya, Turkey \\ *Correspondence: Faculty of Education, Alanya Alaaddin Keykubat University, Alanya-Antalya, Turkey. E-mail: \\ metinozge@gmail.com
}

Received: February 22, 2018

Accepted: February 28, 2018 Online Published: March 19, 2018

doi:10.5430/jct.v7n1p97

URL: https://doi.org/10.5430/jct.v7n1p97

\begin{abstract}
The purpose of this research; a laboratory preschool located in one of the northern states of the United States of America and operating under the Child Development Institute, explains the practices about the Emergent Curriculum and builds a bridge between theory and practice in preschool education. It is thought that bringing good examples of a laboratory school in the United States with a long history in the field of education to the national domain literature will be especially useful for teachers, researchers and specialists working on this field. The method of the study was carried out by the observational case study which is one of the qualitative research designs. In addition, the document analysis method was used to support the information obtained from the observations over time. Obtained data consisted of observations made by the researcher in the preschool, unstructured teacher interviews, and information obtained from the handbook of the kindergarten. The findings are discussed in the headings on the basis of the Emergent Program: Beginning of the day: Arrival in preschool exploration time and gym, large group time/class meeting, activity time and free play, large and small group activities, use of learning centers, outdoor, role of teacher in practice and role of family and parent involvement practices.
\end{abstract}

Keywords: emergent curriculum, observational case study, laboratory school

\section{Introduction}

The laboratory school is a school that works with a university, college or an educational institute that educates teachers, and provides the education of teachers, and is used for professional development. John Dewey, when he opened the first laboratory school at the University of Chicago, aimed firstly to examine the learning styles of children and to develop the education reform (Tanner, 1997). An example of the early childhood education reform that reflects the philosophy of education of Dewey is included in the Reggio Emilia approach that is implemented in the schools of Reggio Emilia and underlies the emergent program (Lindsay, 2015, Malaguzzi, 1998, Rinaldi, 2006).

In the United States of America, the laboratory nursery schools, that are included in the child development and early childhood education departments, has a long and a respectable history. In this country, the establishment of the child development laboratory schools in universities has started in the early 1920s. In the early 1920s, the research on the child development and the early childhood development was performed in the child research institutes established by the financial support of Laura Spelman Rockefeller Foundation. Economist and social scientist Lawrence Frank, who was a visionary thinker worked with the Laura Spelman Rockefeller Memorial Fund, affected the establishment of the "child care research institutes" and the laboratory nursery schools opened based on these institutes, that was connected with the first universities founded in the states like California, Berkeley, Iowa, Minnesota, Michigan, Columbia, Yale, and Detroit (Elicker \& Barbour, 2012).

There are three important aims, which affect each other, of these laboratory nursery schools influenced by the studies of Lawrence K. Frank in Laura Spelman Rockefeller Memorial Foundation. One of these is to make the research, on how children should be educated and how they grow, easier and support them. The second is to provide the model education for children and also to educate the university students on early childhood and child development. The final aim is to spread the knowledge based on the research on child development and child-rearing to parents and public (Clawson, 2003; McBride \& Hicks, 1998; McBride \& Lee, 1995; McBride et al., 2012; Stremmel, Hill, \& Fu, 
2003). Today, these three main aims have continued to be accepted in the laboratory preschools schools in the United States of America and they have turned into the social and educational policies from the 1920s to present.

The third aim doesn't only include providing the education of children for families and societies, it is also to spread the research-based information on the child development and learning of children through the training of the professionals on early childhood programs and the published studies, conferences and the education workshops (Elicker \& Barbour, 2012). These three aims of the laboratory schools, that have established with the support provided for the research on children, are connected to each other. There is a reason why the first aim is the support provided for child research. The child research does not only include understanding and explaining child development and change but also spreading this information and teachers, parents and the other people guiding children. In this way, the process, that has started with research, has turned into teacher education and implementations with the information obtained from children. This transformation has underlain the early childhood education policies in the United States of America, started in the 1920s.

Dewey's point of view towards education that underlies these education policies also underlies the program implemented in the laboratory schools. The programs in the laboratory schools are known to be the programs that have been inspired by the Reggio Emilia approach. It is stated that students are in the center of these programs, they produce, apply and learn information and teachers have the guide and facilitator role.

\subsection{The Emergent Program}

The Emergent Curriculum is a curriculum that is based on children and it underlies the Reggio Emilia approach. This program consists of the learning activities that enable each child's interests, actions concerns that have been incidentally discovered. First of all, teachers make observations and listen to children in order to develop the Emergent Curriculum. The features of the curriculum are briefly as follows:

1. Education doesn't consist of a planned event but learning moments happening in a learning environment and playing.

2. Everything in the world is a program for children.

3. Children organize and reflect their own program.

4. The program has been established on "children learn through playing" philosophy.

5. Children always learn actively through playing.

6. The creative energy results from the inner motivation that occurs when children do whatever they want whenever they want.

7. The curriculum should not focus on lessons but on being active based on planning, activity/action.

8. Children's freedom of behaving according to their interests is a critical factor for the self-confidence and successful self-development of children.

9. There is no certainty of the Emergent Curriculum, children can change it with their answers (Jones,1989).

It is possible to define the Emergent Curriculum in two dimensions: communication and flexibility (Wright, 1997; Pitri, 2006; Buell ve Sutton, 2008). The flexibility dimension is in the two fields of the Emergent Curriculum. It is firstly formed with teachers. When teachers set their targets for activities towards children, they also develop a general hypothesis to arouse the interest of children. Pitri (2006) has stated that a teacher should form the information of the aim of planning the program, get feedback from other children and let them to make selections, in order to provide aims to be bias-free. These hypotheses enable teachers to organize learning materials, arouse the interest of students again to discover what they need. (Seitz, 2006 cited by Martinez, 2014) The second point of flexibility includes the projects that are facilitated by teachers. In their research, Buell and Sutton (2008) have studied with teachers related with the Theme/Project oriented program and determined that teachers ignore the children who are interested in the subjects that are not included in the theme. This determination has demonstrated that even the theme/projects that base the interests of children don't attract all the children's interest. This situation has showed that the interest of children on theme have decreased as the project/program has progressed. Children may become disinterested even in a project emerged from their interests or they may postpone their interest in a way to show it again. In implementing the Emergent Curriculum, the flexibility is the most important aspect of the emergent curriculum in order to enable children to meet their needs and to make more important explorations (Martinez, 2014).

Communication is the second aspect of the emergent curriculum. Communication is the guiding part that is needed 
for the development of the program. According to Seitz (2006) communication occurs through dialogues in implementing the program. These dialogues occur between children and the teachers who records these speeches. This record is considered as a type of documentation. Teachers listen to children during their interaction, take notes and find the starting points in order to establish a new project in accordance with their interests. Dialogue is a way to collect more information on children. Pitri (2006) has suggested that children learn when they interact and they communicate. According to Pitri (2006), when children express their opinions to their peers, they also learn to defend their opinions. Meanwhile, it is possible that they improve their social skills within an active dialogue. This flexibility and communication aspects have revealed that the emergent curriculum has a social side. According to Pitri (2006), these two aspects, in a socio-constructivist approach, provide information to see the theoretical base of the emergent curriculum.

The process that progresses in the emergent curriculum has a spiral structure. Unlike the other programs, this curriculum answers the "What's next? What will be done now?" questions with "It depends". The steps of the spiral process followed by the curriculum and the questions that should be answered by teachers within the process can be listed as follows:

1. Observing play: Teachers observe children's play and they listen to the dialogues in order to obtain information on their thoughts and decisions.

2. Team Meeting: Teachers make team meetings in order to share the notes, especially the ones including the reflective dialogues, they have obtained from their observations, and to bring their observations together and form their meanings.

3. Decision making: Teachers look for answers to the following questions: What are the big play ideas? What are the repetitive play subjects? What are the intriguing thoughts, permanent interests? What are the aims of children and where should we start to understand them? Do they need encouragement and drive to explore more?

4. Planning the Next Step: How are the children's thoughts included in the program? What are the thoughts of children that teachers find important to include in the program? Where and how can this information be included in the program? How should the learning environment be changed and enhanced to support the thoughts, searches of children and what they understand?

5. Progress: After the experiences of children have been included in the program, teacher examines the renewed program and in the final stage, the observation of plays and experiences are revealed. It is important that teachers participate plays and dialogues of children. Meanwhile, teacher reports his/her observations. It is important for the improvement of the program that he/she asks himself/herself these questions: What made you happy? What became a surprise? What has surprised you? How do you answer? What do you want to know? How do you reveal? (Stancey, 2009).

The first step of this spiral process comes from children but it is the teacher who provides the process to continue in the aimed direction. The emergent curriculum emerges from the thoughts of children and it is enhanced with the experiences of teachers. The emergent curriculum is not prepared in advance; it is formed and reported with the experiences of children at the end of the process. For this reason, there is not a program that is taken as a basis in the schools, where this curriculum is included. On the other hand, the emergent curriculum is not planlessness. Teacher forms the aims and skills that he/she determines with a wide perspective, from the interests and the context of the plays of children and he/she includes them in the aims and skills determined in the curriculum. In this way, it becomes a curriculum that has been shaped by children and their interests continue and grow with children. As the emergent curriculum has been formed with the ideas and interests that show up in the plays of children, it may seem hard to reflect all the children's ideas to the curriculum at the same time. Indeed, when it is considered that there are 25 children in a classroom, at least 25 different thought and interest show up during plays. It is very difficult for a teacher to include 25 different ideas and interests in the curriculum and provide every child to benefit from the curriculum. In this stage, it is important that teacher include small group activities as well as large group activities.

Every day, a teacher, who observes the plays of children in the classroom, renews activities, materials, and expectations within a class plan. When the individual webbing of children has been started to be formed, a teacher should write the name of child in the center of the paper, should observe the child during play, write down the interests of the child on the right side of the paper, and should write down the developmental needs, observed by $\mathrm{him} / \mathrm{h}$ r While planning, it is important to examine each child's webbing, choose and need to focus, to examine each child's needs, to form the activities that are suitable for the aims and needs determined by considering the interests of children. (Buell \& Sutton, 2008). 


\section{Method}

This study has been performed by adopting observational case study that is one of the qualitative research designs. According to Yin (2009), the case study is a research method that is used to answer the "how" and "why" questions in the current situations and in the situations where there is no researcher control on the variables. In this research design, it is aimed to examine the situation deeply within its real environment and to describe in detail. (cited by Ozan Leymun, Odabaş1 \& Yurdakul, 2017). The case study does not necessitate the use of a certain data collection method, tool and a data analysis method. These studies are the ones that in-depth examinations are made in, by collecting data from more than one source. The researchers need different types of data in order to develop an in-depth understanding on the examined case. For this reason, the document analysis method has also been used to support the data obtained from the observations in time. Document review consists of the analysis of the written materials that include information on the phenomenon or the phenomena to be researched. (Yıldırım \& Şimşek, 2011, p. 189)

The qualitative research is the research that the qualitative data collection techniques like the unstructured observation, unstructured interview, and document review are used in and that a qualitative process is followed in where the phenomenon and the phenomena are presented in their own environments, in a realistic and holistic way (Yıldırım \& Şimşek, 2011, 39) In the qualitative research, the researcher interviews and interacts with the people in the research sample directly, as the social phenomena should be examined in their own social and cultural context. $\mathrm{He} / \mathrm{she}$ makes interviews in order to present the case that he/she examines, in detail, and he/she uses his/her experiences in the observation process and the data he/she has obtained by the point of view he/she has gained by time and his point of view in the analysis and interpretation process. The researcher himself/herself is a data collection tool. The data he/she wants to obtain is collected through the interaction between the researcher and the individuals, in the sample, or the case. In the qualitative research, the examined process is not intervened; the environmental conditions are not controlled because the social phenomena are shaped according to the environment that they are included. For this reason, the phenomena should be examined in their natural environment and in their natural course, and they should not be generalized for other environments.

The aim of this study is to present the preschool education practices in order to support the daily practices of the preschool educators and the implementers with an inductive approach, in a theoretical perspective. The implementations, especially the ones in the preschool education, have tried to be explained by evaluating them in a sociocultural perspective, on the emergent curriculum base. For this purpose, the following question has been tried to be answered:

1. How are the reflections of the emergent curriculum in the laboratory nursery schools?

The SM Laboratory Preschool, located in one of the Northern States of the United States of America, has opened in 1925 and has been in service in the child development institute that has operated within the university, for 92 years. Like the other laboratory preschools in the United States of America, it has been founded by the universities and the research centers, to make research on child development. It has been stated that the school has three main aims: to demonstrate the example implementations of preschool children and to provide an educational environment for preschool children; to provide education of the preschool teachers at the undergraduate and the graduate level; to be an active center for child studies and research.

The researcher has had interviews on the functioning and the structure of the school; he/she has observed the implementations in the classroom. The observation notebooks have been prepared by making natural observation. The notes have consisted of the unstructured observations of the researcher. In addition to these, the researcher has recorded certain implementations to video.

The observations have been performed in the observation room, in the morning and afternoon classes for seven months and for two days a week. In addition to the notes obtained from the observations, the researcher has made unstructured interviews with the teachers and the managers related to the case he/she has observed. The answers obtained from these interviews have been used to give detailed information on the observed case.

\subsection{Participant}

One of the interviewed teachers is male and he is 35 years old. He has gotten a master's degree from the same university on 2008 and he has 13 years of experience as a teacher. He has been named as R. in the research findings. The other teacher works as a program coordinator in the nursery school. He/she is 40 years old and he/she has been a teacher for 13 years, hs/she has worked as a coordinator for 4 years. He/she has gotten a master's degree from the same university on 2011. He has been named as E. in the research findings. The other person who has been asked 
about her opinion and included in the research findings is an 18 years old female student and she studies and does the internship in the preschool education department of the same university. The researcher, who is an observer in this research, has graduated from early childhood department in 2005 and doctoral degree in 2013.

\subsection{The Context of the School}

2.2.1 The Physical Structure: The preschool operates on the ground floor of the institute, which it operates in, in the mornings and the afternoons. 2 years old children have education in two days a week in the mornings, 3 years of children have education for 3 days a week in the mornings and the 3-5 years of children have education together in a classroom. The education is done in three different classrooms. There are a leader teacher and two candidate teachers in every class. If there is a special child in a class, there is a special education teacher in this class. The teacher-child ratio is generally 1:6. The school has large outdoor playgrounds located in two different areas. As it is a laboratory school, there is a roof in every classroom to observe the children from above. The door of this roof is in different place from the classroom door. It is located at a height of three stairs. From this roof, it is possible to observe the activities in the classroom and this roof can be used in observational research; teachers can watch their implementations and parents can watch the children in the classroom.

2.2.2 The Characteristics of Teachers and Managers: There are two kinds of staff in the nursery school: managers and teachers. The managers are the headmaster, the early childhood program coordinator, the creative program expert, the expert to assist in administrative works. Most of the teachers who teach in these six different classrooms have graduated from the same university where the preschool operates in and they have graduated from the master of early childhood period. Two of the teachers lecture in the undergraduate and master programs of the early childhood in the child development institute. There are two teachers in the classrooms and they teach as the leader teacher in the implementations in turn.

2.2.3 Philosophy of Education and The Daily Program: The preschool has focused on the basic aims of the early childhood education programs by giving service as a center of the example early childhood education implementations for the preschool education teachers training and the active child studies and research. Children learn best in the meaningful contexts related to real experiences and compatible with their developmental skills, and in the learning environments that feed them. As well; children, as individuals learn compatible with their brains. For this reason, it is possible to observe the philosophy suggesting that children learn with their hands, minds, and emotions (Lab School Family Handbook, 2017). The school philosophy takes socio-cultural (children learn from others in their social life) constructivist theories (children construct their meanings from their experiences) and the implementations of Reggio Emilia schools as a basis. The core of these theories and the implementations is to consider children as the means of their own learning and that learning is performed in the context related to their best developmental skills, and in the context of meaningful and paired real experiences, and in the environments with warm and nourishing relationships. The ongoing brain research support these theories and implementations. The "brain-compatible" learning results from the experiences in which "hands are on minds and emotions". Children enjoy the activities for them and they make observations, try, touch, speak, listen, test their ideas, associate, and become skilled in their duties. The focal point of the education included in the program facilitates the curiosity of the children to learn, their research skills, their information about the world, and the starting frame of the academic concepts. The daily program, one scheduled in the morning and one in the afternoon, of the nursery school, is as follows (Lab School Family Handbook, 2017).

7:30-8:30: The arrival of the teachers, environmental planning and discussing the activities to be done during the day.

8:30-8:45: Coming to the preschool: Children undergo a medical examination by the manager. The teachers greet the children and their parents. They take of the clothes of the children, wash their hands.

8:30-09:05: Exploration time and gymnastics: In the meantime, the children can choose from the activities prepared for the day. They deal in some sensory activities, not limited to this period, like the arts, math's, science, problem-solving activities, books, blocks, drama plays, cooking, construction activities, gross motor plays, playing with water and sand.

9.05-9.25: Large group time/ class meeting: This period is the class gathers for a meeting. The teachers plan and organize some experiences to construct concepts and skills. These experiences include the music and motion experiences, stories and dramatizations and concept development in the group discussions which the children attend.

9. 25-10.15 Activity time and small group projects: The children and the teachers play together in the learning centers during the class. The teachers observe, facilitate and support the children's plays and interactions, during the year, from time to time, the children are leaded to research the subjects that they are interested especially in small 
groups. This may occur daily, as a short, focused activity group or officially as a Small Group Project. In the small group projects; 5-7 children come together once to four times a week, depending on the program and the group age, to examine a subject with their teachers. Among the small group projects, there are examining books together, using several art materials, making experiments, watching related videos and discussing them, going on trips, recording and analyzing the data obtained from the observations and participating the discussions in company with the guide.

10.15-10.25: Tidying the classroom up, toilet and washing hands

10.25-10.50: Snacking with all the group: While snacking with the teachers in the classroom, information is tried to be formed by the way that the children communicate with each other, perform shares strengthening the social relationships and with spontaneous conversations.

10.50-11.15 Cleaning, preparation to go out and playing in the playground: The children choose from several activities like climbing, running, digging, cycling, woodwork, role play, and exploration, outdoors in the nature.

11.15-11.30 The end of the day and preparation to go: Story time with all the class and the teacher and parent communication and saying goodbye, while the children are being taken from the school

11.30-12.30 The teachers start the evaluation meeting with the activities done during the day.

\subsection{Research Design}

2.3.1 The role of the school in teacher education: One of the three main aims of the school is teacher training. The teacher candidates, who study in both undergraduate and graduate, gain teaching experience with a leader teacher. Each student is under control of a leader teacher. In the meantime, the leader teacher works with the teacher candidates to help them develop their teaching competencies. The teacher candidates perform the practices with the leader teacher, by taking the leader teacher role for 4 weeks within the implementation process, under the name of "team teaching". The teacher of the class becomes the leader teacher in the implementations to be a model to the teacher candidates for 4 weeks. After, during 10 weeks of the training, 3 teacher candidates teach in the role of the leader teacher for two weeks.

According to this, 6 teacher candidates, 3 of them in each class, study in the classes for 20 weeks, in every weekday. The teacher candidates perform and evaluate their program plans as individual and group activities. They also take responsibility of the leader teacher for 10 weeks. In every year, there are about 40 teacher candidates, who perform teaching practice in the 6 classes of the school. Also, there is a period of time that they discuss with the lead teacher before the children come to class, about their plans regarding the day and they discuss the activities done during the day after the children leave the class.

2.3.2 The place of the laboratory school in the research on early childhood and its characteristics: Supporting the scientific research is among the aims of this laboratory school that is included within the scope of this research, like the other laboratory schools in the United States of America. The laboratory schools have an important role in laying a bridge between the professional practices, theories, and research in the early childhood education field. A researcher, firstly, has to get permission for his/her research from the committee of the university. After the approval of the ethics committee of the university, the implementation is approved again by the headmaster. After, the research offer is reviewed by the school teachers. When the research is approved, if the researcher will do a one-to-one applied research with the children, he/she has to participate the activities in the class for a while to adapt with the children. After the children have adapted to the researcher with the researcher, he/she may invite them to the research room or he/she may stay in the class. The children always have the right to say that they don't want to participate in the research. Most of the preschool children are expected to participate in different research projects. The families receive feedback on the results of the research. When the children participate in a non-observational research, a note is sent to their families for their participation.

The scientific research is as important as the practices and the program in the preschool and the families are expected to participate the research performed during the year. At the beginning of the school year, the parents are expected to sign a permission form to let their children participate the research in the school. For some research, the families are requested to sign a second permission form. The families may request that their children don't participate in a certain research. But they are expected that the nursery school will take into consideration every research related to their children and their children are among participants in the research that require observation. In the classes of the nursery school, there is a room which has an entrance different from the class door used by the students and it is used to observe the class from above, and this room is named as the observation room. The observation room is an area that is above the class and it can't be seen from the class but enables the people in it to see and hear the class. The observation room is used for the scientific research, which is a must of the preschool, to enable the teachers and the 
teacher candidates to observe their practices and enable the families to observe their children in the class. Four or six research is performed during the year. These researches may not include every class.

\section{Results}

The findings of this research have been obtained from the reflective observations and unstructured interviews formed by the researcher. The findings have been tried to be reviewed under the titles of starting the day coming to the nursery school/exploration time/sport, large group time, activity time, free play, large-small group activities, the usage of the learning centers, the usage of outdoors, the role of teacher, the role of family and family participation implementations and inclusion implementations.

\subsection{Starting the Day: Coming to the Nursery School/Exploration Time/Sport}

The children start the day with the question of the day that is on the bulletin board prepared by the teacher. This question varies according to the situations happen within the day. For example, it has been observed that some of the questions have been about the daily possible situations like: "Which birds migrate to south? What's your favorite pizza? How many points do you see here?"After answering the question of the day, they gain experience in the "learning centers" formed by the teachers. For example, there are clay and materials collected from nature, vegetables in a basket, paper and pen on one of the tables. The teacher prepares these materials before the children enter the class and he/she directs them after they enter. The children make their explorations in the areas suggested by their teachers. In the meantime, if they want, the families spend time with the children in these learning centers. In the meantime, the blocks are in the class and the area in which the children come together in the circle time are closed with a curtain. At the time of the large group activity, the curtain is opened and the children start the activity.

The researcher explains his/her observation notes on how the children have spent their time from arriving the nursery school to the large group activities as follows:

"From the arrival to the class to the start of the group time, generally, all the learning centers are opened. The children wait for the group time while they are dealing with the activities in the art center, sand and water center, book corner and jigsaw puzzle table. The teachers have prepared things that the children will deal with and study with, on the tables in the morning. There are teachers with the groups except for the child drawing picture on the easel."

"There are parents in the class. While a child is drawing in the reading and writing corners, his/her mother is with him/her. While another child is observing the insects, he/she is talking about insects with his/her father. The teacher plays with play dough with four children. Two children bead with a trainee teacher. Two children look at the books with the other trainee. In the meantime, the children continue to come and the block corner is closed. When the families bring the children to the class, the families spend time together until the group time."

"Today I came to class earlier. The children have just started to arrive the class. One of the children is doing jigsaw puzzle on his/her own. A child is using a scissor with the help of the teacher. Two children is playing with the water toys in the foam pool with the teacher. The families can enter the class whenever they want."

"When the children come to the class, they play with the clay, dough, waste material and jigsaw puzzle, on the table. Three children play with the clay on the clay table. A child looks at the papers in the reading and writing area. A child draws picture with the waste materials on the plane table. Each group of children deal with their activities under the teacher's guiding. In the meantime, the children can deal with the books, they can be busy with the jigsaw puzzles or they look at the pictures they have drawn on the computer."

It has been observed that the teacher has directed the reflections of the emergent curriculum to learning in the period named exploration time. The main aim in the period named exploration time is to establish the learning opportunities that will arouse the curiosity of the children within the scope of the opportunities provided by the teacher. In the emergent curriculum, as it arouses from the activities during the day, the exploration time is also a period when the program is formed. The transition from the exploration time to group time starts with a simple child song, sung by the teacher. With this song, the children understand that they pass to the large group time. The teacher opens the separated area with a folding screen and the children start to come together in this area.

\subsection{Large Group Time}

In the large group time is time when the children sing songs, talk about what they have experienced in the day. The teacher mostly forms a learning opportunity from a subject that a child has explored while coming to the school that arouses from the interests of the child. For example; a situation that has been heard about has formed the question 
while starting the day and the subject discussed in the group time. One the children in the class has had a sibling recently and "Do you have a sibling?" has been asked as the starting question of the day. The children have attached their photos on the magnetic board regarding whether they have siblings or not. In the large group time, they have talked about this subject and read a book on it. On another day, they have talked about an animal that has been brought to the class before. The class animal has been a hamster and they have read a book about hamsters, they talked about what they eat. They have expressed opinions on how frequently its cage needs to be cleaned.

This situation has a flexibility that can be transformed into a daily program flow which the emergent curriculum forms the basis of. The Emergent Program is also a program constructed with the interests of children, just like in this school. It is a program arousing from the spontaneous interests of a group of child and directed by the ideas, information, questions, and sensations of them. As the aim of the preschool education is to reach every child, it is possible to observe that there is not a significant and limited program in the classes that the qualified program approaches are implemented in. For this reason, the teachers, who want to reach the interests of all the children in the class, should prefer the qualified and applicable sides of the preschool education programs (Buell \& Sutton, 2008).

The research summarizes the transition period from the exploration time to the large group activities as follows:

"After, when the large group time has come, the blocks center has been opened and the children have come together there. As the children have been from different countries, they have sung songs in their mother languages. They have sung in English and French. After the routine songs, news, and conversation directed by the leader teacher, he/she has shown on a whiteboard, where there are the learning centers and the photos of the children, in which areas the children can play and he/she has directed the children to these areas. Playing in these places are not limited and without rules. After spending time in the learning center where the teacher has directed to, the children can pass to other areas when they wanted. Every day the three centers that have been determined before are open: drama center, block center and sand-water center."

Although the children have spread out the centers, as shown on the whiteboard with their photos, it has been observed that this situation has been disappeared after some time. When he/she has been asked why such an implementation has been performed, the teacher R. has said: "Due to their personal characteristics and interests, some children always use the same learning areas and they usually play the same games. He/she has stated that the aim is "to provide every child the experiences of all the learning areas, even in a short period".

The other class teacher E. has explained this as follows: "There are some reasons why we do this. Firstly, we want every child to benefit from every centers in the class. Secondly, we see that some of children have not explored some centers, we especially direct these children to there. Also, we try to take precautionary for the possible negative behavior, so we direct some children to the gymnastics room in the mornings. So, they spend their energy. Finally, some of children never play together. We try to get these children together in certain centers. While doing these, we certainly do not limit the children. After playing in these areas for a while, they go to the areas they want."

The researcher has done observations that have verified these explanations. The researcher has explained this situation as follows:

"It has caught my attention; the children playing in the block center are younger and the children, who have not played before, have been taken to the block center, the children, who generally play, have been directed to the art table."

"The class teacher has shown which child will play where in the activity time and in the free play, on the whiteboard. 1. They examine the plant on the table of the group by using light/flashlight. Then they draw the picture of the plant they examine on the art table. 2. The children in the group make an example of the plant on the clay table. 3. The children in the group wash the dishes in the sand-water center. The children playing in these groups start to walk in the class and play. Some children may continue the group activities until the snack."

Based on this observation and the statements of the teachers, the role of the teacher becomes important. In the emergent curriculum, teacher guides children in the individual and group plays and directs them to learn. In order to find answers to the questions formed by the teacher aimfully, they are encouraged to try different ways. The child who is directed to different areas becomes a part of a program that is formed according to his/her needs and gains experience.

\subsection{Activity Time and Free Play}

The children, who are directed to the learning centers by their teacher, play and gain experience in the learning areas determined by the teacher. It has been observed that the teachers have taken place in the plays with the children. 
"The children, who have been grouped, have been for about 10 minutes in the determined places and most of them have moved to the block area and play drama. Some children have stayed in the centers that the teacher has directed according to their interests."

"While other children are playing in the block area, three children examine a plant with magnifying glasses in the science learning area. The teacher divides the plant into three. He/she puts a piece from the root in front of each child. They have started to examine the roots with the magnifying glasses.

"The teachers have also notified the passage time to the children with a song. The teachers have begun to sing and the children have started to collect the toys. No rush or hurry has been observed. While a teacher sings the song, the other teacher may read books with the children. They have tried to come together in about 10 minutes."

\subsection{Large-Small Group Activities}

It has been observed that they have passed to the small group activities in the following weeks but not the first week. In the unstructured interview done with him, the class teacher E. has stated this situation as follows:

"The important thing for us is that the children play freely, we think that play is the best way to know each other. For this reason, we give place to the small group activities in the following weeks. If you have paid attention, even we have divided into the small groups, one of the groups continue to play."

The information on the content of the small group activities and how it is implemented are as follows:

"The teacher divides the children into small group activities as in he/she shows in the whiteboard. Today the children have been divided into three groups. The first group has left the class. This group glues the wood, trunk and soil that they have collected outside. The second group has come together on the desk. The children in this group are working with watercolors and papers. They get new colors by mixing the colors. The teachers speak about the colors outside. There are red, yellow, green, autumn colors. The aim is only to mix the colors and get new colors. The third group speaks about the insects in the block center. The father of one of the children performs the small group activity with the teacher. They will speak about the insects. They examine two boxes with ants and the other living creatures. They examine a huge dead spider. They look at the spider in other sizes. The teacher asks questions. They examine the real insects put in the lenses. A child asks a question. There is a microscope. They put the lenses in the microscope and they examine them. The father tells what the children see in the lenses. They look into the microscope in turn. The father takes a huge alive insect in to his hands and shows it to the children. The children, who want to touch, touch it. The insect walks on his arm. They talk about how it walks. They examine the scorpion in a box. The father gives information on the time they exist in the world and their population. When one of the children asks why they are so big, the father answers: "They are so big to stay alive in the places they live. If they are smaller, the other insects eat them."

The observations verifying the statement of the teacher in the unstructured interview done with him/her that even they are in the groups they continue to play are as follows:

"After the teacher has divided the children as he/she has showed in the photos of the areas, the children in the first group have sat on the table with the waste material. They will work with clay and the waste material. The children in the second group are playing with the teacher. The children in the third group have gone outside. They continue to make a product in the corridor in front of the class with the trunk, leaves, and wood they have collected on the previous day."

\subsection{The Use of the Learning Centers}

In the emergent curriculum, the learning areas in each class where the children will spend time with the activities they have chosen are significant. These learning areas are ready in a way that the children can reach and use any time. They may be adapted to meet your individual preferences. Also, they may be formed again in order to renew their interest in a certain area. (Metin Aslan, 2017). The observations of the research on the usage of the learning centers are as follows:

"The materials in the learning centers change weekly or monthly. There is always clay in one of the three tables in the class, art activity materials done from the waste materials on the other table and jigsaw puzzles on the third table. The jigsaw puzzle table changes according to the activities within the day. For example, this table is used in the kitchen activity. The other two tables is kept ready for the children to form their activities. In the snack time at noon, the three tables are prepared by the students to have the snacks on them."

"The child on duty that day prepares the tables. The teacher only shows which table he/she will put, the children have delivered the glasses. Everyone pours milk into their glasses. There is dried fruits in the snack, the children put some 
from a big bowl in front of their napkin in turn."

It has been observed that the learning centers have changed and complete each other by looking at daily conditions (seasonal conditions, trips, special conditions) within the scope of the children's interests. Also, it is notable that there are some significant, fixed materials in the learning centers that make them important. For example, in the science learning center, there is a microscope, tools to examine the insects, an alive insect's pool. It has been observed that this learning center has been used in the group times that are determined by the teacher. There are also two computers in the center.

"There are seeds in the science corner in this week/month. There is the seed type and six different boxes under the photos of the plants. The children make classifications by looking at the photos."

It has been observed that the learning areas complete each other. In addition to the observation of the day above, it has been observed that the children have examined a flower that has burst bud in recently with magnifying glasses.

"As they have gone to a post-office before. a post-office has been made in the drama corner. Based on a situation that he/she has observed during free play, the teacher formed a counting opportunity. They have taken the abacus and they count in ten."

"In the reading and writing center, there are the pictures of the children in the two boxes in divided areas. The children draw pictures or write letters and send them to their friends. He/she pastes his/her own picture or the picture of his/her friends picture, who he/she will send the letter, and gives it to his/her friend."

Also, the writings in the learning areas draw attention. For example, it is important that the "How can you change the clay?" question is on the clay table, even the literacy level of the children are not adequate.

There is an area where the pictures of the teacher and the children are hung and this area is also used as a place where the children write notes to their classmates and hang them to the string. The researcher has explained the situation that every center in the class are used as a learning area, as follows:

"All the learning areas are everywhere. They don't remove anything. The smell boxes that they have worked with are staying there and they have increased in number. They don't remove the activity here; there are no teacher tables, no teacher cupboards. Everything is at places that are accessible by the children. And the teachers are everywhere with the children."

The learning areas are used especially when the children have just come to school and they are presented in the environments that they can explore self-learning.

"When they come to school, in other words, until the large group activity starts, generally all the learning areas are kept open. The children wait for the activity in the art area, foam pool and reading and writing area. There are teachers with the groups except for the child who is drawing picture alone."

\subsection{Outdoor Play}

The children have the opportunity to play outside every day unless it is too cold, too hot, rainy or high-polluted. The children are dressed according to the change in the air. In the general policy of the school, it is stated if a class can go out then all the classes can go out. If the families don't want their children to go out, they have been told to come and take them for that day. It is notable that this policy is for keeping the outdoor playing of the children. If a child has a breathing problem when he/she is exposed to the cold weather, the families are requested to get a written note from their pediatrist explaining that situation. (Lab School Family Handbook, 2017).

The observer tells his/her outdoor experiences in the school, as follows:

"Although winters are very cold in here, the children have gone outside every day as demonstrated in the daily program. Especially, the all the summer program has passed by playing outside. They have had their mid afternoon snack in the garden. The teacher plays with the children outside, he/she directs them to play rather with sand, water, trees, branches, stones, and plants but he/she doesn't limit the garden toys like the slide or swing. "

\subsection{The Role of Teacher}

It has been observed that the teacher is both a guide and an observer. Observing the children doesn't mean to know what the child does at any moment. As the emergent curriculum is formed with the interests and explorations of children, a teacher has to watch and observe to reveal these. While the teacher enables the child to know himself/herself by providing feedback to the child, he/she also materializes these learning moments. What is materialized is, in a sense, the evidence what the children learn. These evidences are named as documentation, in accordance with the philosophy of the program. The aim of the documentation is to catch the interests, ideas, theories 
and learning processes of the children and form a source for the next learning time. Also, it enhances the metacognitive cognitive skills (thinking about thinking) of children. The children can take what they understand further by having conversations on what they know. The teacher uses photos, examples of the works of the children, directly the statements of the children to make what the children have learned permanent. There have been remarkable observations of the researcher in this subject.

"The teachers play with the children, especially in the free play. It has been observed that they prefer the garden toys less, especially in summers. It is remarkable that most of the children play in water, sand, long-short pipes areas that have been constructed with the leadership of the teacher. The teacher takes the photos of the children in the areas they play and notes their statements on his/her little notebook."

"The teachers take photos on the acts of the children in the small group activities and play times. They always carry their cameras in their pockets. They also carry little notebooks to write the statements of the children."

"Teacher E. have participated the children while they are playing "a bus game" and has played the bus conductor role. The children have pretended to buy tickets from their teachers and aligned in the back side of the bus."

"The children participate in the activities, "facilitated" by their teachers, in the class with their peers. After, they can finish the activities that they have started in the arrival/exploration time or they can choose the additional activities in the class."

Jones and Nimmo (1994) have suggested that it is possible to understand what children learn and what they want to know more by only observing and recording the plays of children. For this reason, a teacher has the observer, participant, guide, director, bringing their interests into open roles in the emergent curriculum. While the program is improving with the children, the teacher has also the role to shape and transform with the feedback received from children.

The teacher has also a role in educating the trainees. They become the leader of a trainee for 10 weeks. There is a period after the school day where the implementations are discussed. How this period is useful for the students are told as follows:

"When we have a conversation with our leader teacher on our implementations at the end of the day, we remember what we have done and we receive feedback about the daily difficulties, in this way we know the children faster and explore their sides that will form the program faster."

\subsection{The Role of Parent and Parent Involvement}

It has been observed that the families have been allowed to be in the class from the arrival of the children to the circle time and it has been determined that the family participation activities have continued simultaneously with the other activities. It is possible to see the family involvement especially in the small group activities and when starting the day. An example of the family involvement in the small group activities has been included above. The observer has explained the other involvement situations as follows:

"There are again parents in the class. While a child is drawing in the reading and writing corners, his/her mother is with him/her. While another child is observing the insects, he/she is talking about he insects with his/her father."

"The families stay in the class until the large group time. They even participate in the large group activities."

"The atmosphere of the class is as follows: three children play with clay on the clay table. A child looks at the papers in the reading and writing area. A child is making picture in the easel. Two children bead with the trainee. One of the families makes pizza with seven children."

"Also, one of the mothers makes cookie with the children. There is another mother in the class. Three children talk to her. Three children look at the books."

In the examples obtained from the observations, it is possible to see that the families have a different role in the emergent curriculum. In the emergent curriculum, the families are assistants of the education that always enhance the program. When the program improves by the guidance of the children, the families explore the ways how they contribute to the education of their children and the ways if information sharing. Also, it is aimed to show how the program is effective in their children's education by providing that the emergent curriculum is understood by the families point of view. The family participation can be provided with the phases of planning the participation process, orientation, the family support role, new ideas, celebrations, cultural experiences, and education (Metin Aslan,2017).

Together with the program, the advantageous physical environment of the school also attracts the families. As each class has an observation room, it becomes easy for the families to observe their children. The participation in the 
classes may be spontaneous and informal or planned. Also, a handbook is used that gives information on the process of the family participation and how they will participate in the program.

\subsection{The Inclusion Practices}

The laboratory preschool suggests an early child participation model that the disabled or non-disabled children play together, improve, and learn together. A common aim has been determined for the children, regardless of being disabled or not. The sense of belonging and being a member of a group, getting in contact in positive social relationships and making positive friendships includes learning and development for every child in order to reach his/her potential. The school is always accessible for the special children (who have identified physical, mental or emotional obstacles). As the special children need to receive qualified counselor assistance before attending school, an Individualized Education Plan or Individual Family Service Plan and a child service plan, to meet the individual needs of the child has been developed (Lab School Family Handbook, 2017).

The observer states its observation on the special children as follows:

"There has been two special needs children in the class. One is with down syndrome and the other is physically disabled. Each child has two different special education teachers. They are with the child during the activities, large group activities. They make use of the cartoons to provide the physically handicapped child (I think he has also perception problems) to choose the next activity when finishing an activity."

"The special education teachers mostly help these children in the small group activities. The child with down-syndrome generally participates in the plays of the other children and the physically handicapped child is generally interested in books."

\section{Discussion}

The aim of this research is to give information on an example preschool period program formed on the basis of the process and philosophy of the laboratory schools, that have a long history. Especially the research on early childhood period in the international literature is done, naturally, with an experimental and descriptive method. It is important for the early childhood literature to include examples of practices of emergent program and lay a bridge between implementations and theories. Also, it is thought to be a good and qualified example for the laboratory preschools operating within universities in Turkey to demonstrate that these schools can be research laboratories; so general information has been provided on the laboratory schools founded in the early 1920s and information on implementations of an example program.

In this laboratory preschool which is thought to be a good example, it is understood that a different program is followed from the starting of the day. Providing that the children think about a question and giving them the opportunity to express their experiences in their answers cause the program to become distinct within the day. It is important for teacher that children have given a different answer or they have no experience related to that question. It is an important step about the operation of the program that the program is started from the child and it is directed to the child again and it is ended in the child. The emergent curriculum doesn't depend on the aims on a straight line that have been determined in advance, constantly grow, evolve and change. What makes this difference is the limitless curiosity, exploration skills, asking skills of the children and their wish to express their thoughts. The children form the program and the program is formed during the plays of the children (Stancey, 2009,11). The program should not be considered to be without programs due to the fact that it is formed with the plays of the children. The teacher provides the contents that will improve the developmental skills of the children like social skills, confidence and emotional well-being, motor skills, creativity, reasoning, problem-solving, memory, language by motivating the children due to the opportunities that are provided by him/her in the class (i.e. starting the day with a question) (Lab School Family Handbook, 2017). Preparing these contents is the responsibility of the teacher within the program.

That the program is formed with the children and it is continuously updateable reveals the important role of the teacher. It is important that the teacher follows the moments that the children explore and share, to form the program and present it to the children. Certainly, it is difficult to follow every moment of exploration and reflect it to the program. For this reason, the teacher should be with the children in the play time that reveals the children interests, what they know and don't know and take a role in their play. It may be tiring in this role that the teacher follows the children, takes notes on what they express, takes photos.

The philosophy adopted by this laboratory school towards the research done on early childhood period reveals itself in the founding purpose. According to Elicker and Barbour (2012), the laboratory preschools can be evaluated as a 
model for the exploration and the information production. The laboratory schools are important to rethink and reconceptualize the new developments in the research and the implementation fields, reconstruct the ways appropriate for the universities' agenda and visions and to combine the new developments in the early childhood development. For this reason, the laboratory schools should renew and develop themselves. That the preschools adopt its role as an active center of child studies and research supports the research done in the field and it also becomes important that they reflect the results of this research to themselves.

It is known that there are more than 30 nursery schools operating under the universities in Turkey. The founding purpose of these schools that are working under the rector/dean /health and culture office or social facilities has been stated primarily to service for the preschool children of the personnel and to perform the academic preschool education research of the academic units. This aim is very far from the general purpose of the laboratory preschools mentioned in this article. Also, it is thought provoking that the support for the academic research is not mentioned in the related directives. When it is thought that preschools operating within the universities in the United States of America have been founded to make research on child development by higher education institutes/universities and research centers; the reason for the lack of research in the field in Turkey is understood. The results obtained in the research on early childhood period become meaningful when they are transformed to the applied fields. Also, according to McBride et al. (2012), the child development laboratory programs can be the institutions that produce and generalize the new information and the perception on the children, families, teachers, curriculum and early childhood class processes. For this reason, in order to change the current perception, a laboratory preschool that will be founded within the universities on the same philosophical basis is essential. In Turkey, the meaningful contributions towards the philosophy and research that will be adopted by the nursery schools operating within the universities are thought to change the point of view towards this field and also early childhood policies.

\section{References}

Buell, M., \& Sutton, T. (2008). Weaving a web with children at the center: A new approach to emergent curriculum planning for young preschoolers. YC Young Children, 63(4), 100-105.

Clawson, M. A. (2003). The dilemma of linking theory and research with practice and innovation in child development laboratory programs. In B. A. McBride \& N. E. Barbour (Eds.), Advances in Early Education and Day Care (Vol. 12, pp. 51-87). Danvers, MA: Elsevier. https://doi.org/10.1016/S0270-4021(03)12003-4

Elicker, J., \& Barbour, N. (2012). Introduction to the Special Issue on University Laboratory Preschools in the 21st Century. Early Education \& Development, 23(2), 139. https://doi.org/10.1080/10409289.2012.649665

Jones, E. (1989). Emergent curriculum: Planning and letting go. Unpublished paper. Pasadena, CA: Pacific Oaks College.

Jones, E., \& Nimmo, J. (1994). Emergent curriculum. Washington, DC: NAEYC

Lab School Family Handbook (2017). Retrieved from http://lab-school.umn.edu/wp-content/uploads/2017/11/LabSchoolFamilyHandbook17-18.pdf

Lindsay, G. (2015). Reflections in the mirror of Reggio Emilia's soul: John Dewey's foundational influence on pedagogy in the Italian educational project. Early Childhood Education Journal, 43(6), 447-457. https://doi.org/10.1007/s10643-015-0692-7

Malaguzzi, L. (1998). History, ideas, and basic philosophy: An interview with Lella Gandini. In C. Edwards, L. Gandini, \& G. Forman (Eds.), The hundred languages of children: The Reggio Emilia approach-Advanced reflections. pp. 49-97. Greenwich, CT: Ablex

Martinez, U. (2013). Literature review: emergent curriculum, the reggio emilia approach, and north American examples of implementation. The Pennsylvania State University. Retrieved from http://www.personal.psu.edu/ubm5000/blogs/research/Martinez_505\%20Literature\%20Review.pdf

McBride, B. A., \& Hicks, T. (1998). Parental and staff member perceptions of laboratory school functions and program quality. Early Child Development and Care, 143, 21-32. https://doi.org/10.1080/0300443981430102

McBride, B. A., \& Lee, J. (1995). University-based child development laboratory schools: Multiple challenges and demands. In S. Reifel (Ed.), Advances in Early Education and Day Care, 7, 95-121.

McBride, B. A., Groves, M., Barbour, N., Horm, D., Stremmel, A., Lash, M., \& Toussaint, S. (2012). Child development laboratory schools as generators of knowledge in early childhood education: New models and 
approaches. Early Education and Development, 23(2), 153-164. https://doi.org/10.1080/10409289.2012.651068

Metin Aslan Ö. (2017). Reggio emilia yaklaşımın temel taşı: yaşayan ve gelişen program (emergent curriculum). (The cornerstone of the Reggio emilia approach: the living and developing program) Erken çocukluk eğitimi mozaiği: büyük düşünceler/fikirler, modeller ve yaklaşımlar (Early childhood education mosaics: great thoughts / ideas, models and approaches), Ed: Doç. Dr. Ebru Aktan Acar. (169 -182), Nobel Yayıncılık, ISBN: 9786053205944, Ankara

Ozan Leymun, Ş., Odabaşı, H. F., \& Kabakçı Yurdakul, I. (2017). Eğitim ortamlarında durum çalışmasının önemi.(The Importance of Case Study Research in Educational Settings) Eğitimde Nitel Araştırmalar Dergisi. Journal of Qualitative Research in Education, 5(3), 369-385. https://doi.org/10.14689/issn.2148-2624.1.5c3s16m

Pitri, E. (2006). Teacher research in the socio-constructivist art classroom. Art Education, 29(5), 40-45.

Rinaldi, C. (2006). In dialogue with reggio emilia: listening, researching and learning. New York; London, Routledge. https://doi.org/10.4324/9780203317730

Seitz, H. J. (2006). The Plan: Building on children's interests. YC Young Children, 61(2), 36- 41.

Stancey, S. (2009). Emergent Curriculum in Early Childhood Settings From Theory to Practice. Redleaf Press.

Stremmel, A. J., Hill, L. T., \& Fu, V. R. (2003). An inside perspective of paradigm shifts in child development laboratory programs: Bridging theory and professional preparation. In B. A. McBride \& N. E. Barbour (Eds.), Advances in Early Education and Day Care (Vol. 12, pp. 89-111). Danvers, MA: Elsevier.

Tanner, L. N. (1997). Dewey's Laboratory School: Lessons for Today. New York: Teachers College Press.

Wilcox-Herzog, Amanda S., \& McLaren, Meridyth S. (2012) Lessons learned: building a better laboratory school. NALS Journal, 4(1), Article 3.

Wright, S. (1997). Learning how to learn: The arts as core in an emergent curriculum. Childhood Education, 73(6), 361-5. https://doi.org/10.1080/00094056.1997.10521140

Yıldırım, A. (1999). Nitel araştırma yöntemlerinin temel özellikleri ve eğitim araştırmalarındaki yeri ve önemi. Eğitim ve Bilim, 23, 112.

Yıldırım, A., \& Şimşek, H. (2011). Sosyal bilimlerde nitel araştırma yöntemleri (Qualitative research methods in the social sciences). Ankara: Seçkin Yayıncılık.

Yin, R. K. (2009). Case study research: Design and methods (4th ed.). Thousand Oaks, CA: Sage 